\title{
A new method: measurement of microleakage volume using human, dog and bovine permanent teeth
}

\author{
Izzet Yavuz* \\ Faculty of Dentistry \\ Department of Pediatrics \\ University of Dicle \\ 21280, Diyarbakir, Turkey \\ Tel: 90412 2488101/3426 \\ Fax: 904122488100 \\ E-mail: iyavuz@dicle.edu.tr \\ Haluk Aydın \\ Chemistry Department \\ Faculty of Sciences \\ Dicle University \\ 21280 Diyarbakır, Turkey \\ Tel: 9041224885501 etx. 3164 \\ Refik Ulku \\ Department of Thoracic Surgery \\ Faculty of Medicine \\ Dicle University \\ 21280, Diyarbakir, Turkey \\ Tel: 90412248800116 ext. 4263 \\ Sadullah Kaya \\ Department of Operative Dentistry \\ Faculty of Dentistry \\ Dicle University \\ 21280, Diyarbakir, Turkey \\ Tel: 904122488101 ext. 3423 \\ Fax: 904122488100 \\ Caner Tumen \\ Faculty of Dentistry \\ Department of Pediatrics \\ University of Dicle \\ 21280, Diyarbakir, Turkey \\ Tel: 904122488101 ext. 3406 \\ Fax: 904122488100
}

Keywords: dye adsorption test, microleakage, tooth.

Abbreviations: methylene blue (MB)

This study investigates the feasibility of a different new approach to determining the microleakage volume associated with dental restorations (Class $V$ cavity restorated with glass ionomer cement + high copper amalgam) and the relative marginal adaptation deficiency of dog, bovine and human permanent teeth in in vitro conditions. Also researched is the appropriateness of using $\mathrm{dog}$ and bovine teeth in in vitro studies rather than human teeth. Our method utilizes the molecular adsorption characteristics of methylene blue. Within the framework of this study, 60 permanent teeth (20 human, 20 dogs and 20 bovine) were used.

*Corresponding author
These groups were evaluated statistically, of which indicated no statistically significant differences $(p>$ 0.05). It was also concluded that this preliminary investigation showed that the new microleakage volume measurement method may be a valuable new technique for the in vitro study of microleakage dynamics around dental restorations.

One of the most important problems of restorative dentistry today is the failure of restorative materials to completely bond to enamel and dentin, causing microleakage. Microleakage has been defined as the passage of ions, molecules, fluids or bacteria between a cavity wall and the applied restorative material. Microleakage has been 
Table 1. Dye penetration scores in all groups $(p>0.05)$.

\begin{tabular}{|c|c|c|c|}
\hline Amalgam + GIC Specimens & $\begin{array}{c}\text { Group } 1 \\
\text { (Human Teeth) }\end{array}$ & $\begin{array}{c}\text { Group } 2 \\
\text { (Dog Teeth) }\end{array}$ & $\begin{array}{c}\text { Group } 3 \\
\text { (Bovine Teeth) }\end{array}$ \\
\hline$N=10$ & Dye penetration & Dye penetration & Dye penetration \\
\hline $\mathrm{N}$ & Score & Score & Score \\
\hline 1 & 3 & 3 & 3 \\
\hline 2 & 3 & 2 & 2 \\
\hline 3 & 2 & 1 & 1 \\
\hline 4 & 1 & 1 & 1 \\
\hline 5 & 1 & 1 & 1 \\
\hline 6 & 1 & 1 & 1 \\
\hline 7 & 1 & 1 & 1 \\
\hline 8 & 1 & 0 & 1 \\
\hline 9 & 1 & 0 & 0 \\
\hline 10 & 0 & 0 & 0 \\
\hline
\end{tabular}

reported as the cause of hypersensitivity of restored teeth, discoloration at the margins of cavities and restorations, recurrent caries, pulp inflammation and failure of endodontic treatment (Tjan and Tan, 1991; Taylor and Lynch, 1992; Yavuz and Aydın, 2005).

Microleakage is determined today by many in vitro techniques with or without thermal cycling, such as staining; scanning electron microscope; bacterial activity; decay; air pressure; chemical agents; markers; neutron activation analysis; radioisotope; ionization; autoradiography and reversible radioactive adsorption. (Tjan and Tan, 1991; Taylor and Lynch, 1992; Sano et al. 1995; Yavuz and Atakul, 2000; Yavuz and Atakul, 2001a; Yavuz and Atakul, 2001b; Yavuz and Aydin, 2005).

The aim of some researchers is to develop an in vitro model to replicate microleakage at a tooth/restoration interface (Iwami et al. 2000; Matharu et al. 2001; Yavuz et al. 2003; Yavuz and Aydin, 2005).

The significant differences between these models and materials suggest that an ideal method for the determination of microleakage has not yet been established.

The aim of this study was to develop valuable an in vitro model to determine the microleakage volume and ability to use dog and bovine teeth instead of human teeth in in vitro studies.

\section{MATERIALS AND METHODS}

Sixty recently extracted teeth were selected by Binocular Stereo Microscope (Olympus Co., Japan) for this study; 20 human permanent premolars, 20 bovine permanent incisors and 20 dog permanent canines were used.

Bovine teeth were obtained from the Department of Anatomy of Veterinary Medicine Faculty, dog teeth obtained by the doctor's degree thesis study with the subject of "Lowering of hypertension by nitroglycerin and niprus treatment on the dogs on which pulmonary hypertension is created through pulmonary legation and comparison of its isotonic effect of $7.5 \% \mathrm{NaCl}$ and $0.9 \%$ on vital parameters", and human teeth were obtained from the Department of Maxillo-Facial Surgery of Dental Faculty (Figure 1).

The twenty teeth for each species were randomly divided into two groups (30 teeth per group). One group was used for dye penetration (control group), other group used to study microleakage volume. Before the cavity preparation and restorative procedure, all teeth were cleaned. Class V cavity prepared on the buccal surface of each tooth. The cavity has had enamel and dentin margins. The cavities had a mesio-distal width of $3 \mathrm{~mm}$, an occluso-cervical length of $2 \mathrm{~mm}$ and a depth of $1.5 \mathrm{~mm}$. 
Table 2. Microleakage volumes in all groups $(p>005)$.

\begin{tabular}{|c|c|c|c|}
\hline $\begin{array}{c}\text { Amalgam + GIC } \\
\text { Specimens }\end{array}$ & $\begin{array}{c}\text { Group 1 } \\
\text { (Human Teeth) }\end{array}$ & $\begin{array}{c}\text { Group 2 } \\
\text { (Bovine Teeth) }\end{array}$ & $\begin{array}{c}\text { Group 3 } \\
\text { (Dog Teeth) }\end{array}$ \\
\hline $\begin{array}{c}\mathrm{N}=10 \\
\mathrm{~N}\end{array}$ & $\begin{array}{c}\text { Volume } \\
\mathrm{mm}^{3} / \mathrm{tooth}\left(10^{-3}\right)\end{array}$ & $\begin{array}{c}\text { Volume } \\
\mathrm{mm}^{3} / \text { tooth }\left(10^{-3}\right)\end{array}$ & $\begin{array}{c}\text { Volume } \\
\mathrm{mm}^{3} / \text { tooth }\left(10^{-3}\right)\end{array}$ \\
\hline 1 & 1.91 & 1.93 & 1.97 \\
\hline 2 & 2.10 & 2.06 & 1.98 \\
\hline 3 & 2.16 & 2.13 & 2.12 \\
\hline 4 & 2.19 & 2.16 & 2.20 \\
\hline 5 & 2.18 & 2.17 & 2.16 \\
\hline 6 & 2.20 & 2.18 & 2.19 \\
\hline 7 & 2.23 & 2.21 & 2.18 \\
\hline 9 & 2.25 & 2.24 & 2.27 \\
\hline 10 & 2.27 & 2.30 & 2.29 \\
\hline
\end{tabular}

The teeth in all groups were restored in the following way: The type 2 light-hardening powder and liquid glass ionomer cement (Variglass VLC, Dentsply, USA) were prepared in accordance with the manufacturer's instructions, applied to the bottom of the preparations and polymerized. (Astralis3, Vivadent, Australia). Following polymerization, all preparations were filled with a high copper amalgam (Cavex Avalloy, Cavex Co., Holland) and 24 hrs later finishing and polishing were performed.

The specimens were subjected to thermo cycling between $5^{\circ} \mathrm{C} \pm 4^{\circ} \mathrm{C}$ and $60^{\circ} \mathrm{C} \pm 4^{\circ} \mathrm{C}$ for 500 cycles. After thermo cycling, the surface of the teeth, up to approximately 1.5 $\mathrm{mm}$ to the restoration, was coated with a layer of nail varnish, melted utility wax and a second layer of nail varnish (Derhami et al. 1995; Iwami et al. 2000; Gungor et al. 2003; Yavuz et al. 2003; Olmez et al. 2004; Yavuz and Aydin, 2005).

The methylene blue (MB) solution was prepared to a concentration of $\mathrm{MB} 4.75 \mathrm{~g} / \mathrm{l}$. A stock solution was prepared using a buffer of $\mathrm{H}_{2} \mathrm{PO}_{4}^{-} / \mathrm{HPO}_{4}^{-2}$ (phosphate / biphosphate) with a $\mathrm{pH}$ of 6.98 and $24 \mathrm{hrs}$ did storage the specimens in the MB solution. Section made at the middle of the restorations to examine dye penetration.
In our study, the first stage was to evaluate the marginal leakage of specimens to confirm using the dye penetration test (microscope at a magnification of $\mathrm{x} 25$ ). The results were evaluated using the microleakage score; $0=$ no dye penetration; $1=$ dye penetration between the restoration and the tooth up to one-third of distance between the tooth surface and the axial wall; $2=$ dye penetration extending beyond one-third of the distance between the tooth surface and the axial wall; $3=$ dye penetration extending two-thirds of the distance between the tooth surface and axial wall; $4=$ dye penetration reaching the axial wall; and $5=$ dye penetration reached the allof axial wall (Figure 2, Table 1) (Yavuz and Atakul, 2000; Yavuz and Atakul, 2001a; Yavuz and Aydin, 2005).

The second stage of this research was the measurement of the volume of the marginal gaps. In this stage, each individual sample was quantitatively measured using the chemical molecular characteristic properties of MB.

Theoretically, the volume measurement method was created and applied as described below.

The MB molecule is made up of an acid combined with an organic base. Its molecular weight is $\left(\mathrm{M}_{\mathrm{A}}=319.868 \mathrm{~g} \cdot \mathrm{mol}^{-1}\right)$ and a single piece of the absorbed covers an area of $(\mathrm{s})=120$ $\mathrm{A}^{02}$ on the surface (Aydin and Tez, 1996) (Figure 3). 
Absorption is the accumulation of dissolved molecules over the surface of a solid matter, the dissolved molecules could be atoms or ions of matter present in any solution of a gas, vapour or liquid phase. The phase, which allows the accumulation to occur on its surface, is known as the absorber (the teeth), the matter, which accumulates, is known as the absorbed (MB) (Davies, 1952; Nelsen et al. 1952; Aydin and Tez, 1996).

Absorption, in the liquid form, is usually measured using an indirect method. After the experiment, the teeth were dissolved in a $50 \%$ solution of nitric acid, the MB that filled the microleakage gaps dissolves into the solution and it's the $\mathrm{MB}$ concentration is determined.

To draw the calibration graph, a part of the MB solution was taken and determined to have a wavelength of $664 \mathrm{~nm}$ in a spectrophotometer $1_{\max }$ (maximum absorption wavelength).

Some of the MB stock was taken and diluted (10 different concentrations were prepared using $100 \mathrm{ml}$ of distilled water in each beaker to dilute the $2 \% \mathrm{MB}$, ranging from 0 $\mathrm{mL}$ added to $180 \mathrm{~mL}$ added in $20 \mathrm{~mL}$ increments ) to form a series of solutions of varying concentration. These varying concentrations were measured for their absorption wavelengths. These measurements were then used to construct the calibration graph (Figure 4): $\mathrm{A}=\mathrm{E} C$ (A: absorption, E: molar absorption coefficient, $\mathrm{C}$ : concentration).

The molar absorption coefficient was determined to be $170.57 \mathrm{dm}^{3} \cdot \mathrm{cm}^{-1} \cdot \mathrm{g}^{-1}$.

After the calibration graph was drawn, the concentrations were calculated using the absorption values.

In the absorption experiments of our study, the teeth were placed in three joje balloons along with $100 \mathrm{ml}$ of MB solution. The teeth were subjected to MB dye penetration at $37^{\circ} \mathrm{C}$ for a $24 \mathrm{hrs}$ period, to allow dye penetration into any possible existing gaps between the tooth substance and the restorative material (Yavuz and Atakul 2000; Yavuz et al. 2003; Yavuz and Aydin, 2005).

Afterwards, the tooth tissue around the restoration surfaces was removed in a block by making cuts $1.5 \mathrm{~mm}$ around the restored area (Figure 5, Figure 6). These blocks were then dissolved separately in $50 \%$ nitric acid (Figure 7) and the amount of $\mathrm{MB}$ absorption was calculated using the previously created calibration graph. These values were converted to volume values $(\mathrm{V}=\mathrm{m} / \mathrm{d})$ and the individual tooth volume values are reported in Table 2.

\section{FINDINGS}

Table 1 shows the scores of the degree of dye penetration for all groups. Measurement values of the MB staining in groups following the volume measurements of the three groups and the MB molecular counts equivalent to median values are shown in Table 2.

In our study, the first stage was dye penetration. We used Kruskal-Wallis non-parametric test. The differences were not statistically significant between all groups $(\mathrm{p}>0.05)$.

In the second stage of this research, another three groups were evaluated statistically for microleakage volume at the restorations/cavity wall interface. The measurements in all groups were compared using One Way ANOVA Test and groups had no statistically significant differences $(\mathrm{p}>$ $0.05)$.

\section{DISCUSSION}

The in vivo microleakage phenomenon and the adaptation of filling materials into the cavity walls under clinical and laboratory conditions constituted the focal points of researchers for many years and a variety of methods have been used to research this (Tjan and Tan, 1991; Yavuz and Atakul, 2001b; Yavuz, 2003; Kelsey et al. 2004; Turgut et al. 2004; Ersin and Eronat, 2005). Some of these laboratory models have been successfully used to in order to determine microleakage, but they are not quantitative methods.

It is interesting that, despite the effect microleakage has on the health of dental pulp was established, little progress has been made in characterizing the dynamics and nature of microleakage.

In fact, in the studies of dye penetration, the dentin staining was observed to be more different than the actual gaps between cavity walls and restoration materials. This resulted in the use of a dye with a particle diameter equal to the bacterial size or smaller by researchers (around $2 \mu \mathrm{m}$ ) (Yavuz and Aydin, 2005).

In this study, a $2.00 \%$ solution of the MB molecule was used (one MB molecule $=1.2 \mathrm{~nm}^{2}=120 \mathrm{~A}^{02}$ ) since the particle size is less than that of the bacterial one. MB molecules were used because the also dissolve as monomer and bimer in an aqueous environment in which the $\mathrm{pH}$ is adjusted to 6.98 with a phosphate and biphosphate buffer (Nelsen et al. 1952; Yavuz and Aydin, 2005).

Another important issue in microleakage studies arises from the scoring systems. Since the evaluation in those studies largely depends on the observer's interpretation, the leakage scoring is at best a semi-measurable method (Yavuz and Aydin, 2005).

Various studies performed show that the dye leakages in different sections taken at different places of the restorations may show significant differences (Yavuz and Atakul, 2001b). For this reason, the accuracy of a leakage study based on a single section made from a tooth may be negligible. 
As of today, there are no quantitative methods applicable and valuable for the microleakage determination; we have above indicated the amount of microleakage through quantification.

In the stereo microscopic studies, the method is based on the interpretation of the leakage of dye on the cavity wall and is defined as a semi-quantitative approach where the leakage is calculated solely at the surface where the section is made (Yavuz and Atakul, 2001b; Yavuz and Aydin, 2005).

In our method, the researcher's observation and interpretation do not come into play in the determination of microleakage volume quantity and all surfaces where a leakage occurs between tooth/restoration material is quantitatively measured by a chemist.

When the three groups were compared for microleakage volume measurements using the One Way Anowa Test, there weren't statistically significant difference $(p>0.05)$, also the dye penetration test (control groups), evaluated using the Kruskal-Wallis non-parametric test confirmed our method and the results had no significant difference $(\mathrm{p}>$ $0.05)$.

The comparison and/or relationship between the results obtained from the new method and the conventional method (control group) has been found similar.

The aim of this study was to develop an in vitro model to determine the microleakage volume. As a result of this study, the relative microleakage volumes of dog and bovine permanent teeth to human permanent teeth in in vitro conditions was found to be similar.

Within the limitations of these experiments, the following can be concluded, the ability to use dog and bovine teeth instead of human teeth in in vitro studies was confirmed.

It was also concluded in this preliminary investigation that the method of measuring the microleakage volume can be best a valuable tool for the in vitro study of microleakage dynamics around dental restorations, and this method can be use as a new technique for the determination of microleakage volume.

Further work to establish the true scope of the model remains to be undertaken, but this preliminary investigation shows promise.

\section{REFERENCES}

AYDIN, Haluk and TEZ, Zeki. Comparative determination of the adsorption capacities and possible fields of usage of active carbons prepared from the shells of walnut and hazelnut through some commercial active carbons. Turkish Journal of Chemistry, 1996, vol. 16, p. 51-58.
DAVIES, R.G. The use of benzene adsorption isotherms in evaluating the surface and pore characteristics of activated carbons. Chemistry and Industry, February 1952, vol. 23, p. 160-165.

DERHAMI, K.; COLI, P. and BRANNSTROM, M. Microleakage in class 2 composite resin restorations. Operative Dentistry, May-June 1995, vol. 20, no. 3, p. 100105.

ERSIN, Nazen K. and ERONAT, Nesrin. The comparison of a dentin adhesive with calcium hydroxide as a pulpcapping agent on the exposed pulps of human and sheep teeth. Quintessence International,2005, vol. 36, no. 4, p. 271-280.

GUNGOR, Hamdi Cem; TURGUT, Melek Dilek; ATTAR, Nuray and ALTAY, Nil. Microleakage evaluation of a flowable polyacid-modified resin composite used as fissure sealant on air-abraded permanent teeth. Operative Dentistry, May-June 2003, vol. 28, no. 3, p. 267-273.

IWAMI, Yukiteru; YAMAMOTO, Hidetoshi and EBISU, Shigeyuki. A new electrical method for detecting marginal leakage of in vitro resin restorations. Journal of Dentistry, May 2000, vol. 28, no. 4, p. 241-247.

KELSEY, W.P.; LATTA, M.A.; MEARA, J.D.; BARKMEIER, W.W.; HAMMESFAHR, P.D. and JEFFERIES, S.R. An accelerated in vitro model for adhesive testing. American Journal of Dentistry, October 2004, vol. 17, no. 5, p. 323-326.

MATHARU, S.; SPRATT, D.A.; PRATTEN, J.; NG, Y-L.; MORDAN, N.; WILSON, M. and Gulabivala, K. A new in vitro model for the study of microbial microleakage around dental restorations: A preliminary qualitative evaluation. International Endodontic Journal, October 2001, vol. 34, no. 7 , p. 547-553.

NELSEN, R.J.; WOLCOLTT, R.B. and PAFFENBARGER, G.C. Fluid exchange at the margins of dental restorations. Journal of the American Dental Association, March 1952, vol. 44, p. 228-295.

OLMEZ, Aysegul; OZTAS, Nurhan and BODUR, Haluk. The effect of flowable resin composite on microleakage and internal voids in class II composite restorations. Operative Dentistry, November-December 2004, vol. 29, no. 6, p. 713-719.

SANO, H.; TAKATSU, T.; CIUCCHI, B.; HORNER, J.A.; MATTHEWS, W.G. and PASHLEY, D.H. Nanoleakage: Leakage within the hybrid layer. Operative Dentistry, January-February 1995, vol. 20, no. 1, p. 18-25.

TAYLOR, M.J. and LYNCH, E. Microleakage. Journal of Dentistry, February 1992, vol. 20, no. 1, p. 3-10. TJAN, Anthony and TAN, Daniel. Microleakage at gingival margins of class $\mathrm{V}$ composite resin restorations rebonded 
Yavuz, I. et al.

with various low-viscosity resin systems. Quintessence International, July 1991, vol. 22, no. 7, p. 565-573.

TURGUT, Melek D.; TEKCICEK, Meryem and OLMEZ, Seval. Clinical evaluation of a polyacid-modified resin composite under different conditioning methods in primary teeth. Operative Dentistry, September-October 2004, vol. 29 , no. 5, p. 515-523.

YAVUZ, Izzet and ATAKUL, Fatma. Evaluation of microleaking in different in vitro restorations of cow permanent teeth. Balkan Journal of Stomatology, March 2001a, vol. 5, p. 42-45.

YAVUZ, Izzet and ATAKUL, Fatma. The comparison of amount of leaking occurred in different sections of in vitro prepared restorations in cow permanent teeth. Balkan Journal of Stomatology, July 2001b, vol. 5, p. 104-107.

YAVUZ, I.; AYDIN, H. and KAYA, S. New method for measurement of microleakage. Türkiye Klinikleri Journal of Dental Sciences, July 2003, vol. 9, p. 79-85.

YAVUZ, Izzet and ATAKUL, Fatma. The comparison of amount of microleaking for in vitro restorations in permanent teeth of human, dog and cow. Balkan Journal of Stomatology, July 2000, vol. 4, p. 103-106.

YAVUZ, Izzet and AYDIN Haluk. New method for measurement of surface areas of microleakage at the primary teeth by biomolecule characteristics of methilene blue.Biotechnology and Biotechnological Equipment, 2005, vol. 19, no. 1, p. 181-187. 


\section{APPENDIX}

\section{FIGURES}

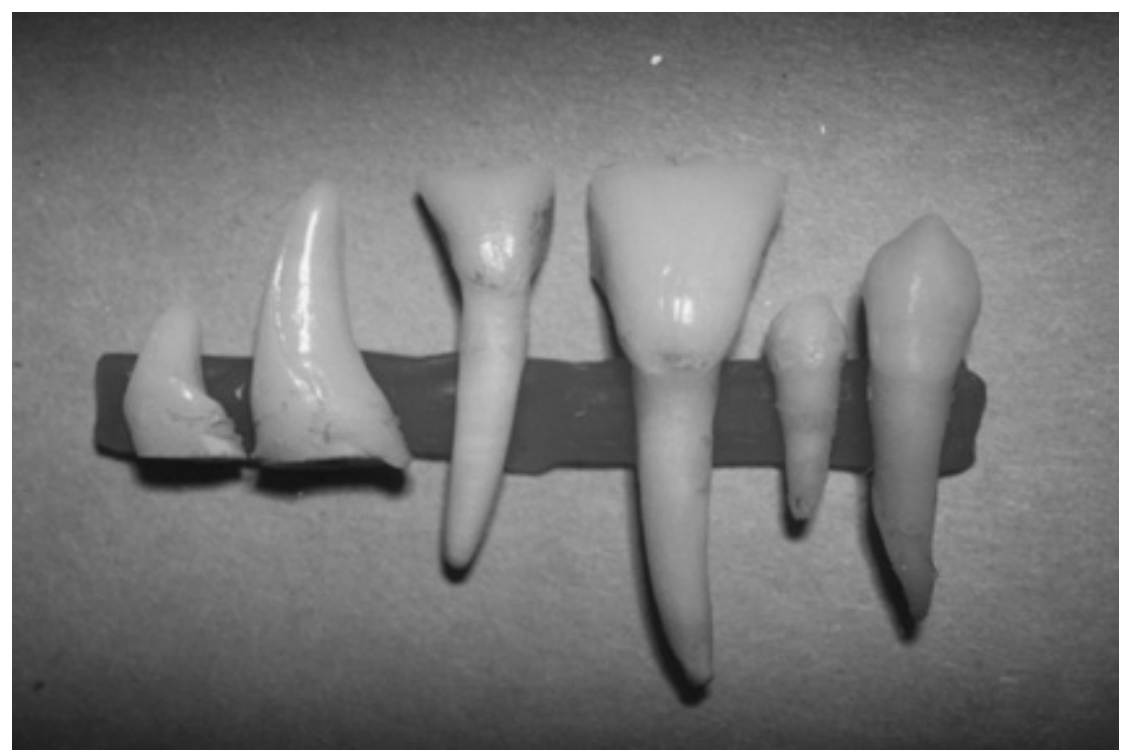

Figure 1. Teeth of dog, bovine and human from left to right side respectively.

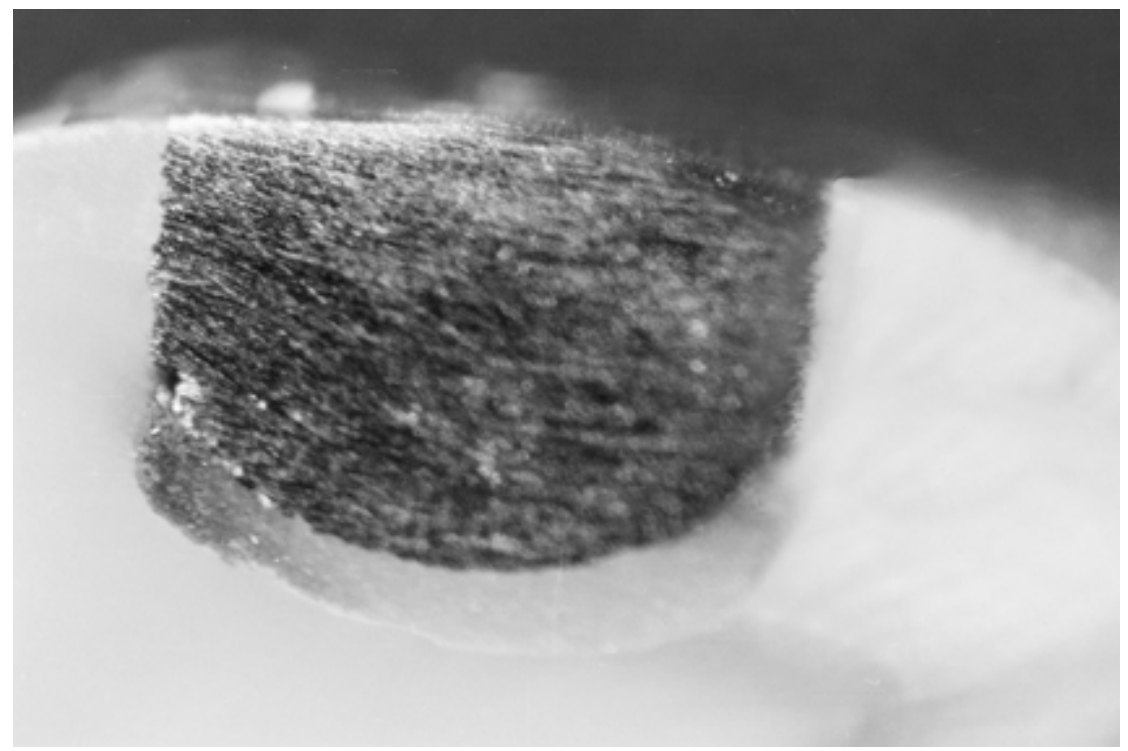

Figure 2. Dye penetration specimen (Magnification x 40). 


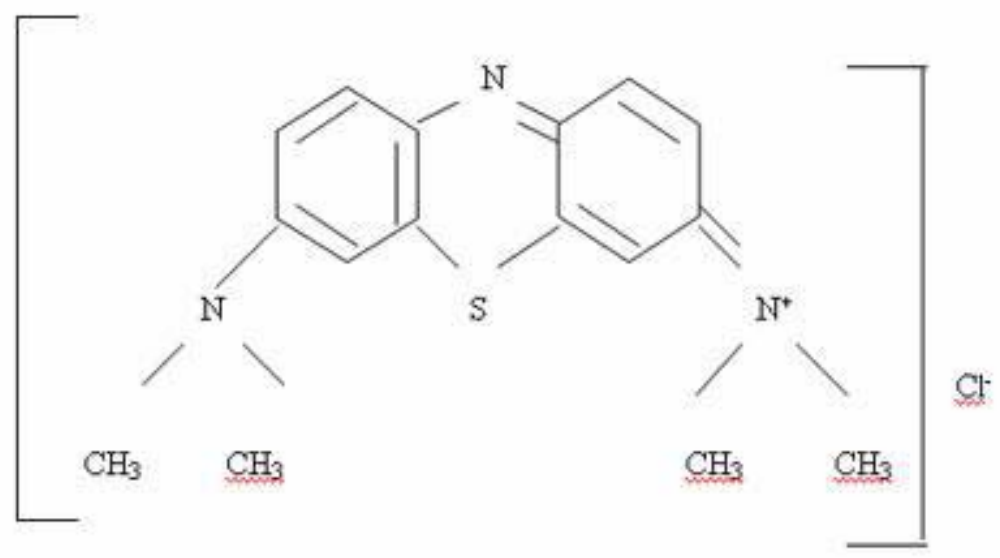

Figure 3. The molecular structure of methylene blue.

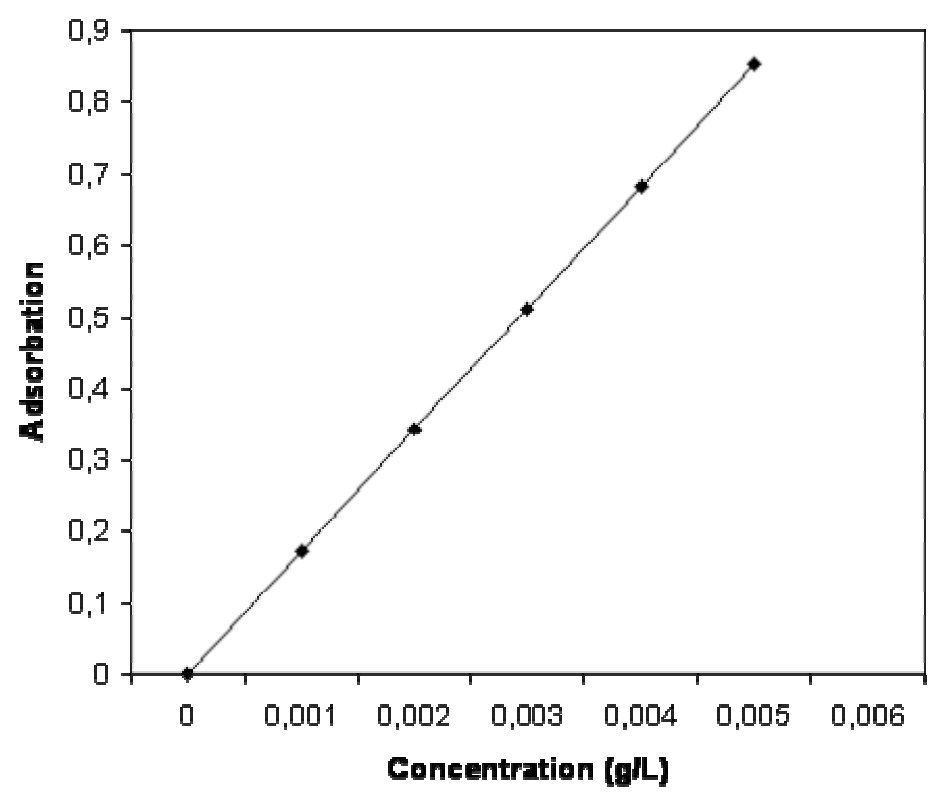

Figure 4. The calibration curve of methylene blue. 


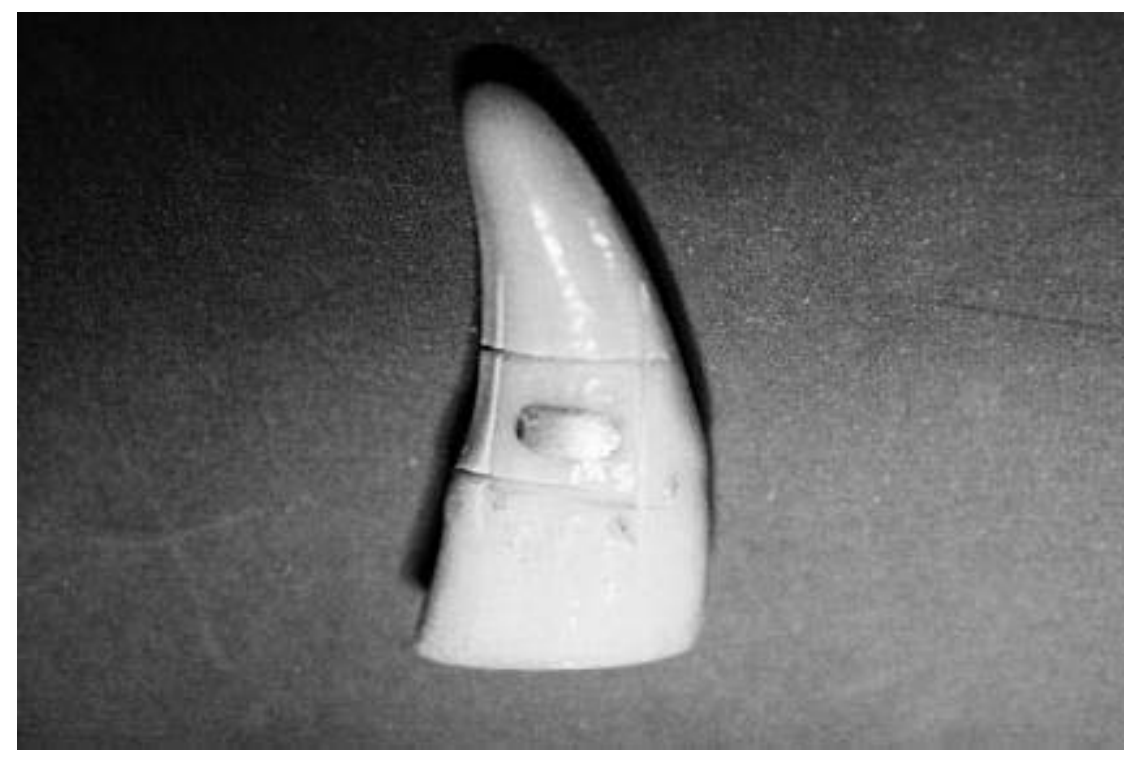

Figure 5. Appearance of cutting model of a specimen.

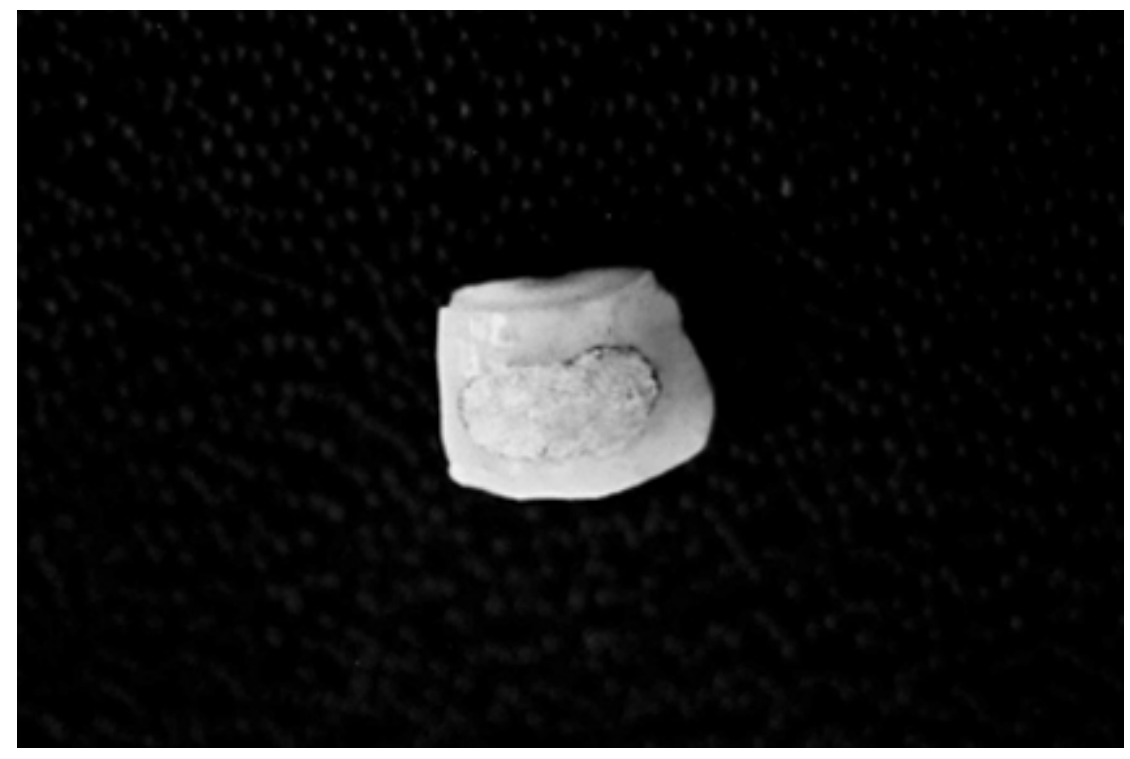

Figure 6. The block of a specimen obtained from tooth (Magnification $\times 10$ ). 
Yavuz, l. et al.

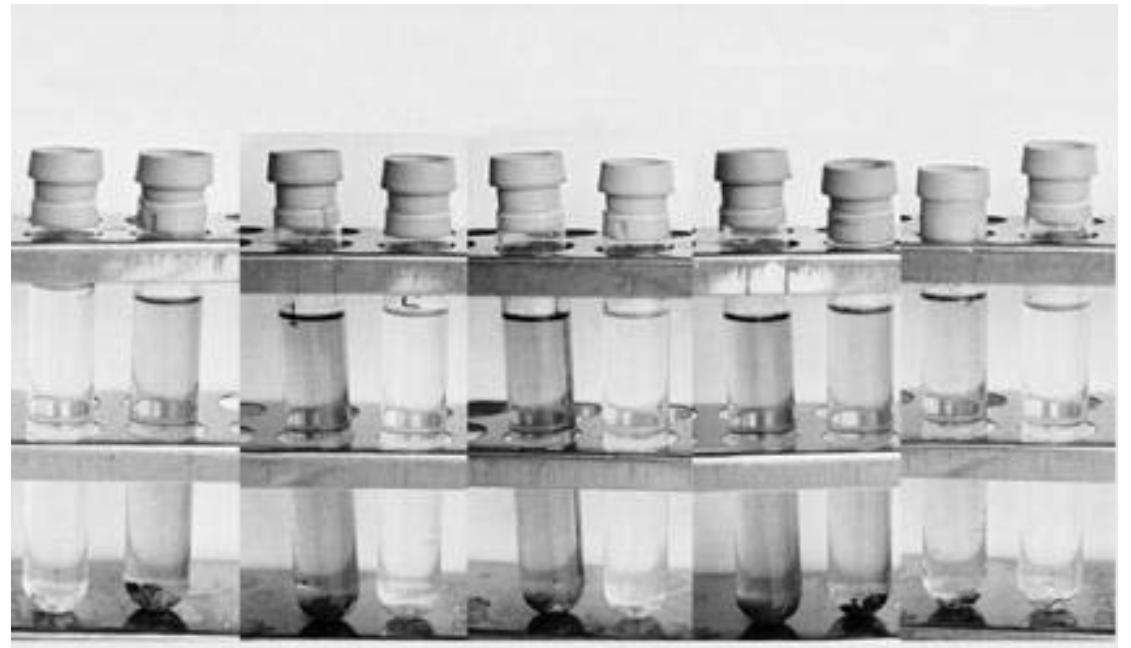

Figure 7. View of melted teeth block specimens in $\mathbf{5 0 \%}$ Nitric acid solution. 